\title{
Identification of Resistant Cultivars for Sheath Blight and use of AMMI Models to Understand Genotype and Environment Interactions
}

\author{
Rajendra Persaud, ${ }^{1,2}$ Duraisamy Saravanakumar, ${ }^{1, \dagger}$ and Mahendra Persaud ${ }^{3}$ \\ ${ }^{1}$ Department of Food Production, Faculty of Food and Agriculture, The University of the West Indies, St. Augustine, Trinidad \\ and Tobago \\ ${ }^{2}$ Department of Plant Pathology, Guyana Rice Development Board, Rice Research Station, Burma, Mahaicony, East Coast \\ Demerara, Guyana \\ ${ }^{3}$ Guyana Rice Development Board, Rice Research Station, Burma, Mahaicony, East Coast Demerara, Guyana
}

\begin{abstract}
One hundred and one rice genotypes were evaluated for response to sheath blight disease under greenhouse and lowland irrigated field conditions in Guyana. The level of resistance varied from highly resistant to resistant in 14 genotypes over five experimental trials. These genotypes were also observed with low area under the disease progress curve values and slow blighting reactions against artificial inoculation of the pathogen. Genotypes GR1568-31-9-1-1-2-1 and cultivar Rustic had susceptible reactions in all experiments. Additive main effect and multipli-

sum of square was attributed to genotype effect, $7.50 \%$ was attributable to environment effect, and $39.52 \%$ was attributable to genotype by environment interaction $(\mathrm{G} \times \mathrm{E})$ effects. The $\mathrm{G} \times \mathrm{E}$ was almost as large as the genotype effect, thus indicating significant differences of genotypes across the testing environments. This revealed that resistance was slightly influenced by the $\mathrm{G} \times \mathrm{E}$. The genotypes that showed stable resistance in all environments in this study could be used for breeding the sheath blight resistance in rice.
\end{abstract} cative interaction analysis was used to study the genotype and environment interactions. The analysis revealed that $52.98 \%$ of the total
Keywords: disease management, field crops, cereals and grains, fungi
Rice (Oryza sativa $\mathrm{L}$ ) is one of the most important crops for agricultural industries in Guyana, and it supports $>10 \%$ of the population. It contributes significantly to the export earnings and gross domestic product of Guyana. The cultivation of rice has been challenged by various pests and diseases. Of diseases, sheath blight (Rhizoctonia solani Kühn [anamorph]; Thanatephorus cucumeris [Frank] Donk [teleomorph]) has become a major disease second to blast in rice-growing regions. The disease was first reported from Japan (Miyake 1910) and has become a serious concern for rice production, especially in intensive cultivation systems. The sheath blight pathogen has wide host range and survives in soil in the form of sclerotia, which makes the disease difficult to control (Willocquet et al. 2011). The disease has been reported to cause yield loss from 5 to $90 \%$ (Gaihre and Nose 2013; Ou 1973; Tang et al. 2007). Nevertheless, yield loss depends on the stage of crop during infection, the extent of infection, susceptibility of the cultivars, and environmental conditions.

The management of sheath blight mainly depends on the use of pesticides in combination with other cultural practices (Liu et al. 2009; Persaud et al. 2019; Willocquet et al. 2000). Other than these practices, the use of host resistance has been considered as one of the most economically and environmentally sound strategies in managing this disease.

${ }^{\dagger}$ Corresponding author: D. Saravanakumar;

Duraisamy.Saravanakumar@sta.uwi.edu

Funding: R. Persaud is thankful to Guyana Rice Development Board (GRDB) for providing the sponsorship to undertake his $\mathrm{PhD}$ research at the University of the West Indies, St. Augustine Campus and conduct experiments at the GRDB, Rice Research Station, Burma in Guyana.

*The $\boldsymbol{e}$-Xtra logo stands for "electronic extra" and indicates that one supplementary table is published online.

The author(s) declare no conflict of interest.

Accepted for publication 19 March 2019.

(C) 2019 The American Phytopathological Society
Nevertheless, no germplasm has been identified to be completely resistant and possess donor-level resistance for development of sheath blightresistant cultivars in rice (Liu et al. 2013; Mew et al. 2004; Pinson et al. 2005; Srinivasachary et al. 2011; Yadav et al. 2015).

The process of identifying stable resistant genotypes across diverse environments has challenges in the selection of suitable assessment techniques and analytical tools. The use of percentage disease severity, area under the disease progress curve (AUDPC) (Prescott et al. 1986), and the apparent rate of disease progress between two observations (Van Der Plank 1963) has offered solutions to determine resistance in genotypes. In addition, the advent of additive main effect and multiplicative interaction (AMMI) analysis has provided an effective approach for studying differential performance of genotypes in varied environmental conditions. This tool can be used for better understanding of genotype by environment interactions $(\mathrm{G} \times$ E) (Mukherjee et al. 2013; Rodrigues et al. 2014). This model incorporates both additive and multiplicative components of the two-way data structure to analyze data.

In spite of an intensive cultivation of rice in Guyana, no cultivar has been identified resistant to sheath blight. Under such circumstances, the identification of resistant germplasm with slow blighting could play a major role in reducing the losses caused by sheath blight. Therefore, the research efforts were made in this study (i) to evaluate relative resistance and ability of rice genotypes to slow down the disease development in 101 rice varieties and (ii) to understand the performance of genotypes under varied environmental conditions and their interactions with environments using AMMI model analysis.

\section{Materials and Methods}

Germplasm used in the study for screening. One hundred and one varieties were evaluated in this study. These varieties were obtained from the Rice Germplasm Collections of Guyana Rice Development Board (GRDB), Rice Research Station (RRS) in Burma. Fifty test entries were from the Observation Yield Trials, 36 were from Advanced Yield Trials, and 15 were from the popular cultivars and varieties grown in Guyana, including susceptible cultivar Rustic.

Isolation, purification, pathogenicity, and virulence test of $\boldsymbol{R}$. solani. The plant samples expressing typical symptoms of sheath blight were collected from the rice fields of the GRDB, RRS, Burma 
and nearby farmer's holding during the spring season of 2015. The samples were transferred to the Plant Pathology Laboratory of the GRDB for isolation of the pathogen (Kazempour 2004).

Rice tillers with sheath blight symptoms including a piece of healthy tissue were cut into small pieces $(0.5$ to $1.0 \mathrm{~cm})$ and surface sterilized with $1 \%$ sodium hypochlorite for $2 \mathrm{~min}$. The cut tissues were then washed three times with sterile distilled water and placed on petri plates containing potato dextrose agar (PDA). The PDA plates were incubated for 5 days at $28 \pm 2^{\circ} \mathrm{C}$. The colony and mycelial characteristics of the fungus on PDA and under a microscope were observed for identification and confirmation of the sheath blight pathogen. After identification, a 5-mm mycelial disc from the actively growing zone of the 5-day-old culture was placed on PDA to obtain pure culture. The pathogenicity of an isolate was confirmed by experiments following Koch's postulates. The virulence test was carried out using five isolates for identifying the most virulent isolate. The agar slants and PDA plates of highly virulent culture were stored at $5^{\circ} \mathrm{C}$ throughout the study and used for artificial inoculation of plants.

Greenhouse screening of rice genotypes under artificial inoculated conditions. Two experiments were conducted under semicontrolled greenhouse conditions during the spring of 2015 and autumn of 2016 at RRS, Burma. The rice genotypes were evaluated against the artificial inoculation of the sheath blight pathogen. Seedlings of the 101 genotypes were grown using standard seed beds in a nursery facility of RRS, Burma. Seedlings of the 101 genotypes including a susceptible check were carefully uprooted at 21 days after sowing and transplanted in concrete bins $(1.5 \times 1.5 \mathrm{~m})$ filled with soil in the greenhouse. Each genotype was planted in a 1.4-m-long row with a $20-\mathrm{cm}$ space between plants. The primary tillers of three hills were selected at 25 days after transplanting and inoculated with sclerotia of 9-day-old culture of $R$. solani. The inoculation was done by gently placing a single sclerotium in the second leaf sheath from the top or into the lowest leaf axis of the leaf sheath just above 5 to $8 \mathrm{~cm}$ above the surface level. After inoculation, the greenhouse was sprayed with water two times a day for 7 days to maintain the relative humidity of 85 to $90 \%$.

Disease severity was recorded at 5, 10, 15, 20, and 25 days after inoculation (DAI). The percentage of disease severity and the AUDPC value were calculated. AUDPC was computed using the following formula (Prescott et al. 1986):

$$
\text { AUDPC }=\sum_{i=1}^{k} 1 / 2\left(S_{\mathrm{i}}+S_{\mathrm{i} 1}\right) \times d
$$

where $S_{\mathrm{i}}$ is the disease severity on the $i$ th day, $k$ is the number of successive evaluations of disease, and $d$ is the interval between $i$ th and $i-1$ th evaluations of disease. The rate of disease development between two observations was calculated using the following formula (Van Der Plank 1963):

$$
r=2.3 /\left(t_{2}-t_{1}\right)\left\{\log X_{2} /\left(1-X_{2}\right)-\log X_{1} /\left(1-X_{1}\right)\right\}
$$

where $r$ is the rate of infection, $1-X$ is the correction factor (the changing quantum of the available host tissue), $t_{1}$ is the time when disease severity score is $X_{1}, t_{2}$ is the time when disease severity score is $X_{2}, X_{1}$ is the disease severity score at $t_{1}$ time, and $X_{2}$ is the disease severity score at $t_{2}$ time.

Field screening of genotypes against sheath blight. The field experiments were carried out under lowland irrigated conditions at Onverwagt Back during the spring and autumn seasons of 2015 and the spring of 2016. The genotypes were evaluated against natural infection of the sheath blight pathogen. The land was prepared at Onverwagt Back following the standard crop production guidelines of the GRDB for rice cultivation. Seeds of each genotype were directly sown in a row $2 \mathrm{~m}$ in length, with $20 \mathrm{~cm}$ between rows. Two rows were maintained for each genotype. The susceptible check Rustic was sown in two rows after every 10 entries and as a border crop surrounding the nursery to ensure the uniformity of disease inoculum for genotypes. Fertilizers were applied at a rate of $\mathrm{N}_{120} \mathrm{P}_{50}$ $\mathrm{K}_{0} \mathrm{~kg} / \mathrm{ha}$ as per crop production guidelines of the GRDB. Three replications were used for each genotype. The observations were recorded from the maximum tillering to flowering stage. Disease severity was assessed by measuring the lesion length and total sheath length of five tillers in a replication. Percentage disease severity was computed using the formula: [total lesion length/total length of sheath $\times 100$ ]. The performance rating was derived from a slight modification of the Standard Evaluation System of the International Rice Research Institute (IRRI) (IRRI 1988) (scale 0: no infection [immune]; $1:<1 \%$ infection [highly resistant]; $3: 1$ to $5 \%$ infection [resistant]; 5: 6 to $25 \%$ infection [moderately resistant]; 7: 26 to $50 \%$ infection [susceptible]; and 9: $>50 \%$ infection [highly susceptible]).

AMMI analysis for $\mathbf{G} \times \mathbf{E}$. The additive effects for the $101 \mathrm{ge}-$ notypes and five testing environments over two locations for sheath blight resistance and the multiplicative term for $\mathrm{G} \times \mathrm{E}$ interaction were analyzed in this study. The disease severity data from five test environments were structured to fit the AMMI analysis. The AMMI statistical model and computational methods described in Gauch (2013) were used. Analysis of variance (ANOVA) was conducted using the computer program MATMODEL version 3.0 (Gauch 2007). AMMI biplot and principal component analysis (PCA) were carried out using the software developed by the IRRI (IRRI 2014). Because the data contain zero for entries showing immune reaction, 0.05 has been included for all of the individual observations to derive the results directly from the biplot graph generated. The normal additive ANOVA was utilized to partition the variation into genotype and environment main effects and the $\mathrm{G} \times \mathrm{E}$ effect. PCA was applied to partition the $\mathrm{G} \times \mathrm{E}$ into several principal components.

\section{Results}

Resistant and slow blighting genotypes for sheath blight. The 101 rice genotypes were evaluated against the sheath blight disease during the 2015 and 2016 cropping seasons under natural field conditions at Onverwagt Back, Guyana. The screening of all genotypes was also carried out under artificial inoculated conditions at the GRDB, RRS, Burma. Sheath blight reactions of the genotypes ranged from immune to susceptible (score: 0 to 7 ) in the three seasons during 2015 and 2016 under field conditions. The genotypes were recorded as resistant to susceptible reactions (score: 3 to 7) in the autumn 2015 and spring 2016 seasons under artificial inoculation conditions (Table 1).

Over the five test environments, FG12-56 and GR1631-35-16-12-1-1 were recorded as having immune to resistant (score: 0 to 3 ) reactions under inoculated and field conditions in the cropping seasons of 2015 and 2016. Five (GR1440-52-23-4-1-1-1-1-2-1-2, GR16026-41-1-1-2-1, IR-94, G11-08, and G98-135) and seven genotypes (FG12-02, FG12-14, FG12-41, FG12-270, G11-103, FG07-35, GRDB-12, and BR-444) were highly resistant to resistant (score: 1 to 3 ) and resistant (score: 3), respectively (Tables 1 and 2). Genotypes GR1568-31-9-1-1-2-1 and Rustic consistently showed susceptible reactions (score: 7) in all seasons tested under natural inoculation and artificial inoculated conditions (Table 2), indicating adequate disease levels for reliable tests. The conditions that prevailed at Onverwagt Back during the two cropping seasons were highly favored for natural occurrence of sheath blight disease.

Twenty-six genotypes had low AUDPC values (50.45 to 99.02) revealing the slow disease development under artificial inoculated conditions during the autumn 2015 and spring 2016 crop seasons (Supplementary Table S1). Of these, 13 genotypes (FG12-56, GR1631-35-16-1-2-1-1, GR1440-52-23-4-1-1-1-1-2-1-2, GR16026-41-1-1-2-1, IR-94, G11-08, G98-135, FG12-02, FG12-14, FG12270, G11-103, FG07-35, and BR-444) were identified with immune to resistant (scores: 0 to 3 ) reactions under field conditions. These genotypes were also observed with resistant reactions and AUDPC values $<100$ against artificial inoculation. Among the 13 genotypes, the lowest AUDPC value was recorded in genotypes FG12-14 (50.45), FG12-56 (52.88), and IR-94 (57.21) during the autumn 2015 crop season. Genotypes G98-135 (42.80), FG07-35 (GRDB-12; 47.16), and BR-444 (48.30) had low AUDPC values in spring 2016. High AUDPC values were recorded in Rustic (549.63 and 482.30, 
Table 1. Reaction of genotypes to sheath blight disease under field and screen house conditions

\begin{tabular}{|c|c|c|c|c|c|c|c|c|}
\hline \multirow[b]{3}{*}{ No. } & \multirow[b]{3}{*}{ Genotype } & \multicolumn{5}{|c|}{ Disease reaction $^{a}$} & \multirow[b]{3}{*}{ PCA1 $^{c}$} & \multirow[b]{3}{*}{ PCA2 } \\
\hline & & \multicolumn{2}{|c|}{ Greenhouse } & \multicolumn{3}{|c|}{ Field } & & \\
\hline & & Aut $^{\mathrm{b}} 2015$ & $\mathrm{Sp}^{\mathrm{b}} 2016$ & $\mathrm{Sp}^{\mathrm{b}} 2015$ & Aut $^{\mathrm{b}} 2015$ & $S p^{b} 2016$ & & \\
\hline 1 & FG12-02d & 3 & 3 & 3 & 3 & 3 & -0.17 & 0.03 \\
\hline 2 & FG12-05 & 5 & 5 & 3 & 5 & 3 & 0.37 & 0.10 \\
\hline 3 & FG12-06 & 5 & 5 & 3 & 5 & 3 & 0.37 & 0.10 \\
\hline 4 & FG12-08 & 3 & 3 & 5 & 5 & 5 & -0.76 & 0.30 \\
\hline 5 & FG12-14 ${ }^{\mathrm{d}}$ & 3 & 3 & 3 & 3 & 3 & -0.17 & 0.03 \\
\hline 6 & FG12-16 & 5 & 5 & 3 & 5 & 5 & 0.15 & 0.22 \\
\hline 7 & FG12-19 & 5 & 5 & 5 & 5 & 5 & -0.17 & 0.03 \\
\hline 8 & FG12-21 & 5 & 5 & 3 & 5 & 3 & 0.37 & 0.10 \\
\hline 9 & FG12-27 & 5 & 5 & 5 & 5 & 5 & -0.17 & 0.03 \\
\hline 10 & FG12-32 & 5 & 5 & 3 & 5 & 3 & 0.37 & 0.10 \\
\hline 11 & FG12-33 & 5 & 5 & 3 & 5 & 5 & 0.15 & 0.22 \\
\hline 12 & FG12-41 ${ }^{\mathrm{d}}$ & 3 & 3 & 3 & 3 & 3 & -0.17 & 0.03 \\
\hline 13 & FG12-56 ${ }^{\mathrm{d}}$ & 3 & 3 & 0 & 1 & 1 & 0.58 & -0.14 \\
\hline 14 & FG12-61 & 5 & 5 & 3 & 5 & 3 & 0.37 & 0.10 \\
\hline 15 & FG12-78 & 5 & 3 & 3 & 5 & 3 & 0.00 & -0.15 \\
\hline 16 & FG12-82 & 5 & 5 & 5 & 5 & 5 & -0.17 & 0.03 \\
\hline 17 & FG12-98 & 5 & 3 & 3 & 5 & 3 & 0.00 & -0.15 \\
\hline 18 & FG12-101 & 5 & 5 & 3 & 3 & 3 & 0.42 & -0.23 \\
\hline 19 & FG12-114 & 5 & 5 & 5 & 5 & 5 & -0.17 & 0.03 \\
\hline 20 & FG12-148 & 5 & 5 & 3 & 5 & 5 & 0.15 & 0.22 \\
\hline 21 & FG12-201 & 5 & 5 & 3 & 5 & 5 & 0.15 & 0.22 \\
\hline 22 & FG12-248 & 5 & 5 & 3 & 5 & 5 & 0.15 & 0.22 \\
\hline 23 & FG12-270 & 3 & 3 & 3 & 3 & 3 & -0.17 & 0.03 \\
\hline 24 & FG12-273 & 5 & 5 & 5 & 5 & 5 & -0.17 & 0.03 \\
\hline 25 & FG12-277 & 5 & 5 & 3 & 5 & 5 & 0.15 & 0.22 \\
\hline 26 & FG12-279 & 3 & 5 & 5 & 5 & 5 & -0.39 & 0.55 \\
\hline 27 & FG12-281 & 5 & 5 & 3 & 3 & 3 & 0.42 & -0.23 \\
\hline 28 & GR1401-13-47-4-1-3-1-1-1-1-1 & 5 & 5 & 5 & 5 & 5 & -0.17 & 0.03 \\
\hline 29 & GR1412-24-32-1-1-1-3-1-2-2-1-1 & 5 & 5 & 3 & 5 & 5 & 0.15 & 0.22 \\
\hline 30 & GR1412-24-32-1-1-1-3-1-2-2-1-1-1 & 5 & 5 & 5 & 5 & 5 & -0.17 & 0.03 \\
\hline 31 & GR1422-34-4-1-2-2-2-1-2-2-1 & 5 & 5 & 3 & 3 & 3 & 0.42 & -0.23 \\
\hline 32 & GR1440-52-23-4-1-1-1-1-2-1-2e & 3 & 3 & 1 & 1 & 1 & 0.42 & -0.23 \\
\hline 33 & GR1447-5-3-2-1-2-1-2-1 & 3 & 5 & 3 & 5 & 5 & -0.07 & 0.74 \\
\hline 34 & GR1447-5-3-2-2-2-1-1-1 & 9 & 3 & 5 & 3 & 5 & -0.06 & -1.59 \\
\hline 35 & GR1493-6-9-1-3-1-2-2-2 & 5 & 3 & 3 & 5 & 3 & 0.00 & -0.15 \\
\hline 36 & GR1493-6-9-1-3-2-1-1-1 & 5 & 5 & 3 & 3 & 3 & 0.42 & -0.23 \\
\hline 37 & GR1493-6-9-1-3-2-2-2-2 & 5 & 5 & 3 & 3 & 3 & 0.42 & -0.23 \\
\hline 38 & GR1600-4-41-1-1-2-1 & 5 & 5 & 5 & 5 & 5 & -0.17 & 0.03 \\
\hline 39 & GR1601-5-2-2-1-2-2 & 5 & 3 & 5 & 5 & 3 & -0.32 & -0.33 \\
\hline 40 & GR1602-6-41-1-1-2-1 & 3 & 3 & 1 & 1 & 1 & 0.42 & -0.23 \\
\hline 41 & GR1617-21-11-1-4-1-2 & 5 & 5 & 3 & 5 & 5 & 0.15 & 0.22 \\
\hline 42 & GR1621-25-19-1-2-1-1 & 5 & 5 & 3 & 5 & 3 & 0.37 & 0.10 \\
\hline 43 & GR1624-28-23-1-2-1-1 & 5 & 5 & 3 & 5 & 3 & 0.37 & 0.10 \\
\hline 44 & GR1629-33-66-2-2-1-1 & 5 & 5 & 5 & 5 & 5 & -0.17 & 0.03 \\
\hline 45 & GR1631-35-16-1-2-1-1 & 3 & 3 & 0 & 1 & 1 & 0.58 & -0.14 \\
\hline 46 & GR1636-40-47-2-1-1-1 & 5 & 5 & 3 & 3 & 3 & 0.42 & -0.23 \\
\hline 47 & GR1637-41-23-1-1-1-2 & 5 & 5 & 5 & 5 & 5 & -0.17 & 0.03 \\
\hline 48 & GR1638-42-33-2-3-1-1 & 5 & 5 & 3 & 3 & 3 & 0.42 & -0.23 \\
\hline 49 & GR1639-43-62-2-2-1-1 & 5 & 3 & 5 & 5 & 5 & -0.55 & -0.22 \\
\hline 50 & Seeraj & 5 & 5 & 5 & 5 & 5 & -0.17 & 0.03 \\
\hline 51 & G07-118 & 5 & 5 & 3 & 5 & 3 & 0.37 & 0.10 \\
\hline 52 & G07-13-1 & 5 & 3 & 3 & 5 & 3 & 0.00 & -0.15 \\
\hline 53 & FG10-26 & 3 & 3 & 5 & 5 & 5 & -0.76 & 0.30 \\
\hline 54 & FG10-54 & 5 & 3 & 5 & 3 & 3 & -0.28 & -0.67 \\
\hline 55 & FG10-103 & 3 & 5 & 3 & 5 & 3 & 0.16 & 0.62 \\
\hline 56 & FL-121 & 5 & 3 & 5 & 5 & 5 & -0.55 & -0.22 \\
\hline 57 & FL-127 & 5 & 5 & 3 & 5 & 3 & 0.37 & 0.10 \\
\hline \multirow[t]{2}{*}{58} & IR-94e & 3 & 3 & 1 & 3 & 3 & 0.15 & 0.22 \\
\hline & & & & & & & \multicolumn{2}{|c|}{ (Continued on next page) } \\
\hline
\end{tabular}

${ }^{\text {a }}$ Mean percentage disease reaction of three replications: 0, immune; 1, highly resistant; 3, resistant; 5, intermediate between susceptible and resistant; 7, susceptible; 9 , highly susceptible.

b Aut, autumn season; Sp, spring season.

${ }^{c}$ PCA, principal component analysis.

d Resistant.

${ }^{\mathrm{e}}$ Highly resistant to resistant (G13 and G45 showed immune response only in field screening during Sp 2015).

${ }^{\mathrm{f}}$ Susceptible. 
respectively) and GR1568-31-9-1-1-2-1 (375.26 and 369.16, respectively) during both seasons.

The percentage disease severity in genotypes against artificial inoculation of $R$. solani ranged from 0.76 to 31.43 . The disease severity was low in GR1447-5-3-2-1-2-1-2-1 and high in susceptible Rustic during autumn 2015. Similarly, the disease severity during spring 2016 ranged from 0.14 to $28.42 \%$, with the lowest incidence observed in GR1568-32-3-2-2-2-1 and the highest incidence observed in genotype GR1568-31-9-11-2-1 followed by Rustic.

The rates of disease development at 5, 10, 15, 20, and 25 DAI were computed to understand the progress of disease over time. The mean increase in apparent infection rate at the exponential growth stage ranged from 0.001 (G11-08) to 0.098 (GR1568-31-9-1-1-2-1) and from 0.001 (FG12-08) to 0.174 (GR1568-31-9-1-1-1-1) in the autumn 2015 and spring 2016, respectively. The mean decrease in

Table 1. (Continued from previous page)

\begin{tabular}{|c|c|c|c|c|c|c|c|c|}
\hline \multirow[b]{3}{*}{ No. } & \multirow[b]{3}{*}{ Genotype } & \multicolumn{5}{|c|}{ Disease reaction $^{\mathbf{a}}$} & \multirow[b]{3}{*}{ PCA1 $^{c}$} & \multirow[b]{3}{*}{$\mathbf{P C A}^{\mathbf{c}}$} \\
\hline & & \multicolumn{2}{|c|}{ Greenhouse } & \multicolumn{3}{|c|}{ Field } & & \\
\hline & & Aut $^{\text {b }} 2015$ & $\mathrm{Sp}^{\mathrm{b}} 2016$ & $S^{b} 2015$ & Aut $^{\mathrm{b}} 2015$ & $S p^{b} 2016$ & & \\
\hline 59 & G11-08 & 3 & 3 & 3 & 1 & 3 & -0.12 & -0.31 \\
\hline 60 & G11-09 & 5 & 5 & 3 & 3 & 3 & 0.42 & -0.23 \\
\hline 61 & G11-28 & 5 & 5 & 3 & 3 & 3 & 0.42 & -0.23 \\
\hline 62 & G11-101 & 5 & 3 & 3 & 5 & 3 & 0.00 & -0.15 \\
\hline 63 & G11-102 & 5 & 5 & 3 & 5 & 5 & 0.15 & 0.22 \\
\hline 64 & $\mathrm{G} 11-103^{\mathrm{d}}$ & 3 & 3 & 3 & 3 & 3 & -0.17 & 0.03 \\
\hline 65 & FG12-23 & 5 & 5 & 3 & 5 & 3 & 0.37 & 0.10 \\
\hline 66 & FG12-29 & 5 & 5 & 3 & 5 & 5 & 0.15 & 0.22 \\
\hline 67 & FG12-49 & 5 & 3 & 3 & 5 & 3 & 0.00 & -0.15 \\
\hline 68 & FG12-259 & 5 & 3 & 3 & 5 & 3 & 0.00 & -0.15 \\
\hline 69 & GR1516-29-16-2-3-1-1-1-1 & 5 & 3 & 5 & 5 & 5 & -0.55 & -0.22 \\
\hline 70 & GR1561-24-23-2-2-1-1 & 5 & 3 & 5 & 5 & 5 & -0.55 & -0.22 \\
\hline 71 & GR1562-25-16-2-1-2-1 & 5 & 3 & 5 & 5 & 5 & -0.55 & -0.22 \\
\hline 72 & GR1562-25-26-1-1-2-1 & 5 & 3 & 5 & 5 & 5 & -0.55 & -0.22 \\
\hline 73 & GR1562-25-26-1-1-2-1 & 3 & 3 & 5 & 5 & 5 & -0.76 & 0.30 \\
\hline 74 & GR1568-31-9-1-1-1-1 & 5 & 5 & 3 & 5 & 5 & 0.15 & 0.22 \\
\hline 75 & GR1568-31-9-1-1-2-1 ${ }^{\mathrm{f}}$ & 7 & 7 & 7 & 7 & 7 & -0.17 & 0.03 \\
\hline 76 & GR1568-32-3-2-2-1-1 & 5 & 3 & 5 & 3 & 5 & -0.50 & -0.56 \\
\hline 77 & GR1568-32-3-2-2-2-1 & 3 & 3 & 3 & 5 & 3 & -0.22 & 0.37 \\
\hline 78 & GR1573-36-9-2-2-1-1 & 5 & 5 & 5 & 3 & 3 & 0.10 & -0.42 \\
\hline 79 & GR1573-36-9-2-2-2-2 & 5 & 5 & 3 & 5 & 5 & 0.15 & 0.22 \\
\hline 80 & GR1575-38-9-1-2-1-1 & 5 & 5 & 5 & 5 & 5 & -0.17 & 0.03 \\
\hline 81 & GR1580-43-2-1-1-2-1 & 5 & 3 & 5 & 5 & 5 & -0.55 & -0.22 \\
\hline 82 & GR1580-43-23-1-1-1-2 & 3 & 5 & 3 & 3 & 3 & 0.21 & 0.28 \\
\hline 83 & GR1583-46-16-3-1-2-1 & 3 & 5 & 5 & 5 & 5 & -0.39 & 0.55 \\
\hline 84 & GR1584-47-8-2-1-2-1 & 3 & 5 & 5 & 5 & 3 & -0.17 & 0.44 \\
\hline 85 & GR1584-47-8-2-2-1-1 & 5 & 5 & 5 & 5 & 3 & 0.05 & -0.08 \\
\hline 86 & GR1585-48-9-2-1-1-1 & 5 & 5 & 5 & 5 & 5 & -0.17 & 0.03 \\
\hline 87 & G06-123 (GRDB-14) & 5 & 5 & 3 & 5 & 3 & 0.37 & 0.10 \\
\hline 88 & GP18 (Aromatic or GRDB 13) & 5 & 5 & 5 & 5 & 5 & -0.17 & 0.03 \\
\hline 89 & FG07-35 (GRDB-12) ${ }^{\mathrm{d}}$ & 3 & 3 & 3 & 3 & 3 & -0.17 & 0.03 \\
\hline 90 & FG05-259 (GRDB-10) & 3 & 3 & 5 & 5 & 5 & -0.76 & 0.30 \\
\hline 91 & G04-08 (GRDB-9) & 5 & 3 & 5 & 5 & 5 & -0.55 & -0.22 \\
\hline 92 & G98-135e & 3 & 3 & 1 & 3 & 1 & 0.37 & 0.10 \\
\hline 93 & G98-30-3 & 5 & 5 & 5 & 5 & 5 & -0.17 & 0.03 \\
\hline 94 & G98-24-1 & 5 & 5 & 3 & 5 & 3 & 0.37 & 0.10 \\
\hline 95 & G98-22-4 & 5 & 5 & 5 & 5 & 3 & 0.05 & -0.08 \\
\hline 96 & G98-196 & 5 & 3 & 5 & 5 & 3 & -0.32 & -0.33 \\
\hline 97 & F7-10 & 5 & 5 & 3 & 5 & 3 & 0.37 & 0.10 \\
\hline 98 & BR- $444^{\mathrm{d}}$ & 3 & 3 & 3 & 3 & 3 & -0.17 & 0.03 \\
\hline 99 & DIWANI & 5 & 5 & 3 & 5 & 3 & 0.37 & 0.10 \\
\hline 100 & IR 22 & 5 & 5 & 3 & 5 & 3 & 0.37 & 0.10 \\
\hline 101 & Cultivar Rustic ${ }^{\mathrm{f}}$ & 7 & 7 & 7 & 7 & 7 & -0.17 & 0.03 \\
\hline
\end{tabular}

Table 2. Environments

\begin{tabular}{lclr}
\hline No. & Environment & \multicolumn{1}{c}{ Environment description $^{\mathbf{a}}$} & PCA1 \\
\hline 1 & E1 & AI at RRS, Burma screen house (autumn season, 2015) & 1.26 \\
2 & E2 & AI at RRS, Burma screen house (spring season, 2016) & -2.10 \\
3 & E3 & FC at Onverwagt Back (spring season, 2015) & 1.02 \\
4 & E4 & FC at Onverwagt Back (autumn season, 2015) & -1.88 \\
5 & E5 & FC at Onverwagt Back (spring season, 2016) & -0.75 \\
\hline
\end{tabular}

a AI, artificial inoculated condition; E, environment; FC, field condition; RRS, Rice Research Station. 
infection rate at the exponential growth stage ranged from -0.001 (GR1621-25-19-1-2-1-1) to -0.062 (GR1601-5-2-2-1-2-2) and from -0.001 (FG12-78) to -0.003 (FG12-98) in the autumn 2015 and spring 2016, respectively.

The genotypes FG12-98, FG12-270, and GR1601-5-2-2-1-2-2 showed a continuous decrease in the disease development rate over three consecutive periods in autumn 2015. However, only one genotype, FG12-98, had the reduction in disease development over three observation periods during the spring of 2016. Five genotypes (FG12-56, GR1440-52-23-4-1-1-1-1-2-1-2, GR1602-6-41-1-1-2-1, G11-103, and FG07-35) had consistent decreases in disease development at least over one observational period during both of the seasons. Genotypes FG12270 , G11-08, and BR-444 were observed with a decrease in disease development during autumn 2015 over three, two, and one observation period, respectively. Likewise, the genotypes FG12-14, GR1631-35-16-12-1-1, and G98-135 had a decrease in progress of sheath blight in at least one observation period during spring 2016.

AMMI analysis. The AMMI ANOVA results of the 101 genotypes evaluated against sheath blight over the five test environments revealed that $52.98 \%$ of total sum of square (SS) was attributed to the genotype effect, whereas $7.50 \%$ was attributed to environment effect, and $39.52 \%$ was attributed to $\mathrm{G} \times \mathrm{E}$ effects. PCA1 and PCA2 have collectively contributed to $68.50 \%$ of the total SS, where PCA1 captured about $46.10 \%$ of the interaction SS in $25.75 \%$ of the interaction degrees of freedom. Similarly, PCA2 accounts for $22.40 \%$ of the $\mathrm{G} \times \mathrm{E}$ effect (Table 3 ). Because the $\mathrm{G} \times \mathrm{E}$ effect was almost as large as the genotype effect, the AMMI analysis seemed to be useful. Based on the ANOVA results, interaction principal components analysis 1 (IPCA1) and IPCA2 were statistically significant, and therefore, the two IPCAs captured the real interaction signal in the data. The size of the $\mathrm{G} \times \mathrm{ESS}$ was 1.34 times smaller than that for the SS for genotype, and it was also 5.27 times larger than that for environment, thus indicating that the differences of the genotypes across the environments were significant. The results indicated that the resistance seemed to be influenced by the $\mathrm{G} \times \mathrm{E}$ effect (Table 3 ).

The AMMI1 biplot. The genotypes and environment falling over vertical broken lines in the AMMI1 biplot had similar means. Genotypes G78 (GR1573-36-9-2-2-1-1), G33 (GR1447-5-3-2-1-2-1-2-1), G84 (GR1584-47-8-2-1-2-1), G99 (DIWANI), and G76 (GR1568-32-3-22-1-1) had similar means (Fig. 1). Similarly, the genotypes that fall almost on a horizontal line had similar interaction patterns (G33: GR1447-5-3-2-1-2-1-2-1; G78: GR1573-36-9-2-2-1-1; G84: GR158447-8-2-1-2-1; G55: FG10-103; G65: FG12-23; G82: GR1580-43-231-1-1-2; G55: FG10-103; G59: G11-08; G77: GR1568-32-3-2-2-2-1; G85: GR1584-47-8-2-2-1-1; and G34: GR1447-5-3-2-2-2-1-1-1). These results revealed that the environments of field-testing conditions E3 (Onverwagt Back, spring 2015), E4 (Onverwagt Back, autumn 2015), and E5 (Onverwagt Back, spring 2016) had opposite interaction patterns compared with the environments of artificial testing conditions E1 (Burma, autumn 2015) and E2 (Burma, spring 2016) (Fig. 1).

Table 3. Analysis of variance of additive main effects and multiplicative interaction on the genotype and environment interactions ${ }^{\mathrm{a}}$

\begin{tabular}{lrrrrrr}
\hline Source & df & \multicolumn{1}{c}{ SS } & \multicolumn{1}{c}{ MSS } & \multicolumn{1}{c}{$\begin{array}{c}\text { Estimated } \\
\text { SS }(\boldsymbol{\%})\end{array}$} & $\boldsymbol{P}$ value \\
\hline TRT & 504 & 729.95248 & 1.44832 & 3.51 & & 0.00000 \\
GEN & 100 & 386.75248 & 3.86752 & 9.36 & 52.98 & 0.00000 \\
ENV & 4 & 54.72475 & 13.68119 & 33.11 & 7.50 & 0.00000 \\
G $\times$ E & 400 & 288.47525 & 0.72119 & 1.75 & 39.52 & 0.00056 \\
IPCA1 & 103 & 130.17908 & 1.26387 & 3.06 & 45.13 & 0.00000 \\
IPCA2 & 101 & 62.81425 & 0.62192 & 1.51 & 21.77 & 0.02101 \\
IPCA3 & 99 & 55.40613 & 0.55966 & 1.35 & 19.21 & 0.06979 \\
Residual & 97 & 40.07579 & 0.41315 & & 13.89 & \\
\hline
\end{tabular}

a TRT, treatment; df, degree of freedom; ENV, environment; $F$, calculated $F$ value; $\mathrm{G}$, genotype; $\mathrm{G} \times \mathrm{E}$, genotype $\times$ environment interaction; IPCA, interaction principal components analysis; MSS, mean sum of square; $P$, probability; SS, sum of square.
Similarly, genotypes G85 (GR1584-47-8-2-2-1-1), G34 (GR1447-5-32-2-2-1-1-1), G38 (GR1600-4-41-1-1-2-1), G75 (GR1568-31-9-1-1-2-1), and G101 (Rustic) displayed on the right side of the vertical broken lines revealed higher disease scores and susceptibility than those on the left side. Likewise, genotypes G54 (FG10-54), G55 (FG10-103), G82 (GR158043-23-1-1-1-2), G77 (GR1568-32-3-2-2-2-1), G58 (IR-94), G59 (G1108), and G92 (G98-135) appear on the left side of the vertical broken line, revealing lower disease scores with a greater resistance (Fig. 1). The placement of environments E1 (Burma, autumn 2015), E2 (Burma, spring 2016), and E4 (Onverwagt Back, autumn 2015) on the right-hand side of the midpoint of the main effect axis in the AMMI1 biplot suggested that these environments were slightly more favorable for the sheath blight screening experiment. The placement of E3 (Onverwagt Back, spring 2015) and E5 (Onverwagt Back, spring 2016) environments on the opposite side indicated that they were slightly less favorable (Fig. 1).

In addition, E4 (Onverwagt Back, autumn 2015) followed by E1 (Burma, autumn 2015) observed with small PCA1 scores revealed low interaction, great stability, and adoption to the test environments. The high PCA1 scores in E3 (Onverwagt Back, spring 2015) and E2 (Burma, spring 2016) indicated the high interaction effect and reflect more specific stability and adoption to specific environment (Fig. 1). Likewise, a large proportion of genotypes $(87.3 \%)$ had relatively small PCA1 scores ranging from 0 to 0.42 (either positive or negative) and showed small interactions, which was one of the reasons for clustering of the genotypes on the biplot (Fig. 1), although a considerably smaller proportion of genotypes $(12.7 \%$ ) had high PCA1 scores $>0.50$. Genotypes G4 (FG12-08), G53 (FG10-26), G76 (GR1568-32-3-2-2-1-1), and G90 (FG05259 GRDB-10) had the highest PCA1 score of 0.76 followed by genotypes G13 (FG12-56) and G11 (FG12-33) with PCA1 scores of 0.58. Genotypes G49 (GR1639-43-62-2-2-1-1), G56 (FL-121), G69 (GR1516-29-16-2-3-1-1-1-1), G70 (GR1561-24-23-2-2-1-1), G71 (GR1562-25-16-2-1-2-1), G72 (GR1562-25-26-1-1-2-1), G81 (GR1580-43-2-1-1-2-1), and G91 (G04-08 GRDB-9) had low PCA1 scores of 0.55 (either positive or negative). These results implied the high interaction effect, reflecting more specific stability and adoption to specific environment (Tables 1 and 2).

AMMI2 biplot display (IPCA1 versus IPCA2). In the AMMI2 biplot, more responsive genotypes and environments are displayed

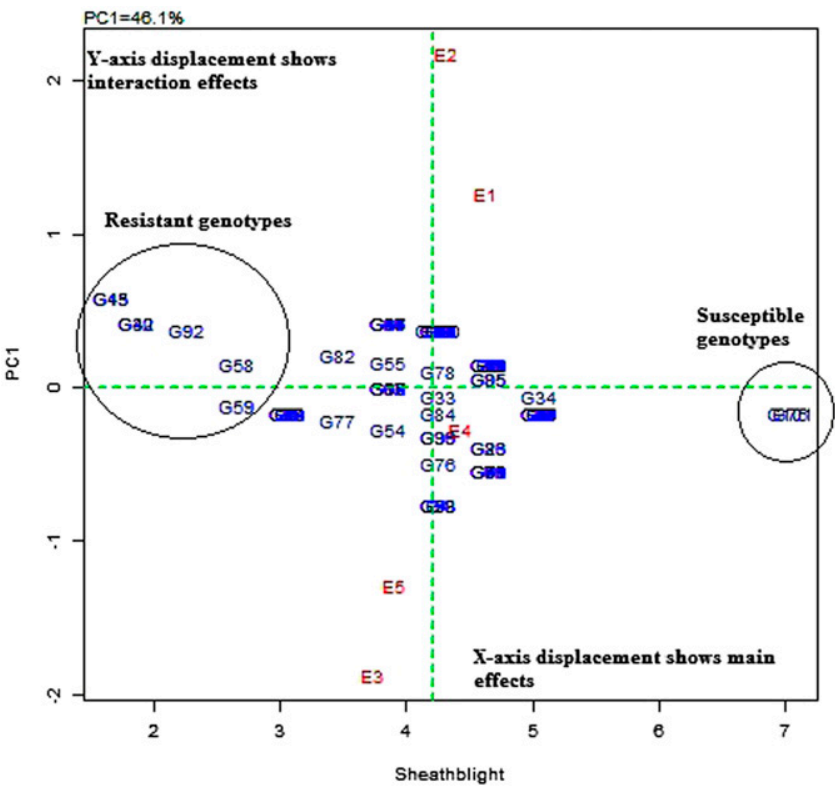

Fig. 1. Additive main effect and multiplicative interaction 1 biplot displaying sheath blight disease reaction and interaction principal components analysis 1 scores of genotypes at five environments. E1, Burma, autumn 2015; E2, Burma, spring 2016; E3, Onverwagt Back, spring 2015; E4, Onverwagt Back, autumn 2015; E5, Onverwagt Back, spring 2016; G, genotype; PC, principal component. 
away from the origin. E1 (Burma, autumn 2015), E2 (Burma, spring 2016), and E3 (Onverwagt Back, spring 2015) were the most differentiating environments, whereas G34 (GR1447-5-3-2-2-2-1-1-1) was the most responsive genotype followed by G76 (GR1568-323-2-2-1-1), G54 (FG10-54), G45 (GR1631-35-16-1-2-1-1), G55 (FG10-103), and G33 (GR1447-5-3-2-1-2-1-2-1) (Fig. 2).

The genotypes and environment falling in the same sector interacted positively; when located on opposite sides, they interacted negatively. The genotypes and environments observed in adjacent sectors had complex interactions. However, a majority of genotypes were closer to each other and clustered near the origin, which indicated that those genotypes expressed more stable sheath blight

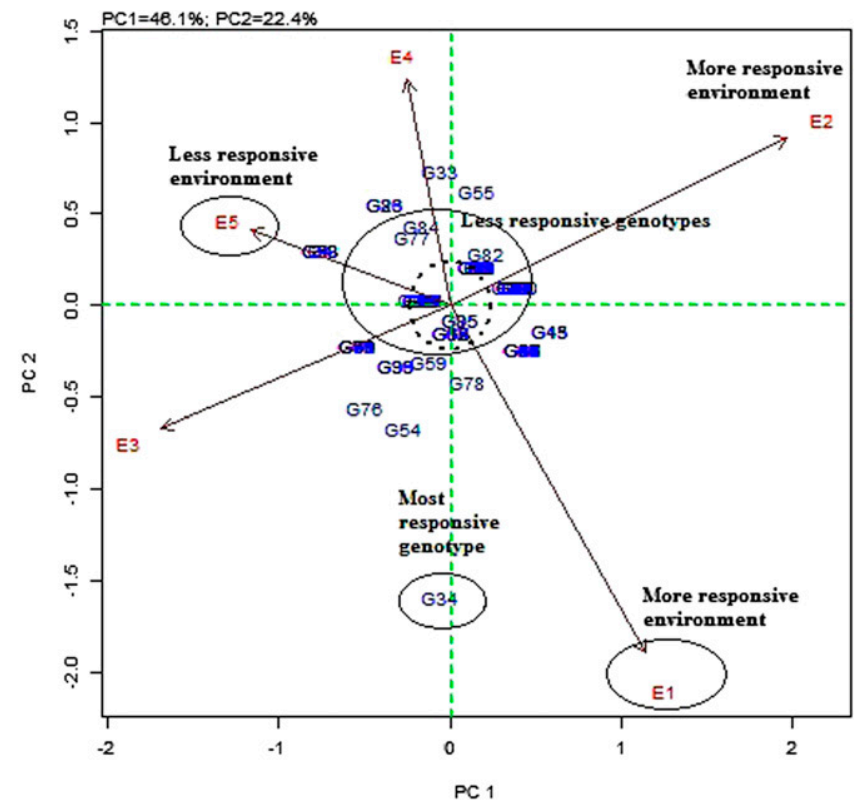

Fig. 2. Additive main effect and multiplicative interaction 2 biplot displaying genotypes and environments in the first and second principal component (PC) axis. E1, Burma, autumn 2015; E2, Burma, spring 2016; E3, Onverwagt Back, spring 2015; E4, Onverwagt Back, autumn 2015; E5, Onverwagt Back, spring 2016; G, genotype.

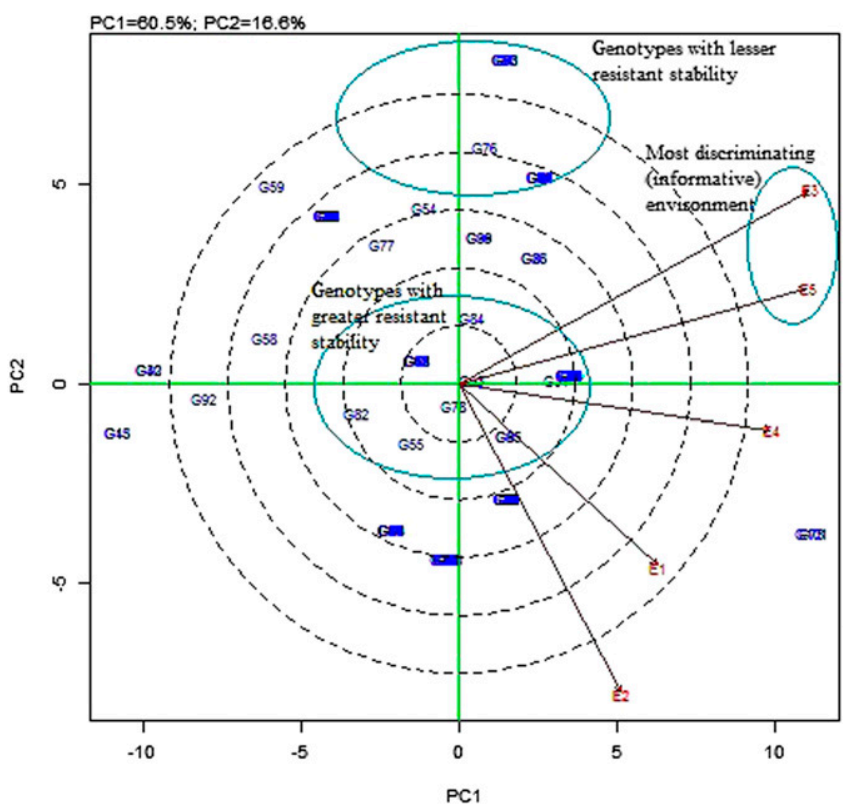

Fig. 3. Genotype $x$ environment biplot displaying the performance of genotypes in test environments. E1, Burma, autumn 2015; E2, Burma, spring 2016; E3, Onverwagt Back, spring 2015; E4, Onverwagt Back, autumn 2015; E5, Onverwagt Back, spring 2016; G, genotype; PC, principal component. resistant reaction and had similar performance. The genotypes closer to a particular environment indicated that they had better adoption to specific environments. It is quite visible from the biplot that genotypes G33 (GR1447-5-3-2-1-2-1-2-1) and G84 (GR158447-8-2-1-2-1) falling close to E4 (Onverwagt Back, autumn 2015) were particularly suitable and showed stable sheath blight response in that environment. The genotypes (G34: GR1447-5-3-2-2-2-1-11 and G54: FG10-54) that were between E1 (Burma, autumn 2015) and E3 (Onverwagt Back, spring 2015) indicated highly stable disease response in those environments (Fig. 2).

Genotype plus genotype $\times$ environment biplot for environment view of sheath blight. The genotype plus genotype $x$ environment (GGE) biplot explained $77.1 \%$ of the total variation of the GGE. The biplot showed that E3 (Onverwagt Back, spring 2015) and E5 (Onverwagt Back, spring 2016) seem to be the most discriminating (informative) environments, whereas E1 (Burma, autumn 2015) was the least discriminating environment (Fig. 3).

The display of average environment axis (AEA) was used to explain the ideal test environment for sheath blight. The E4 (Onverwagt Back, autumn 2015) test environment was considered as the best for sheath blight testing because of its placement in the biplot close to the "average environment" and "ideal test environment" followed by E1 (Burma, autumn 2015) and E5 (Onverwagt Back, spring 2016), which also showed a smaller angle with AEA and were observed to be the most representative environments. The environments away from AEA (E2 Burma, spring 2016 and E3 Onverwagt Back, spring 2015) from the biplot were proposed as the least representative (Fig. 4).

The biplot explained that the genotypes scattered apart from the origin and distanced away from each other could be considered as different in terms of the sheath blight resistant status. These genotypes also showed less stability and contributed greatly to both genotypes and $\mathrm{G} \times \mathrm{E}$. The biplot also explained that the genotypes clustered close to the origin could be considered as similar in terms of their sheath blight resistant status. These genotypes expressed greater stability and had little contribution to both genotype and $\mathrm{G} \times \mathrm{E}$. These variations were owing to the mean sheath blight score of genotypes and/or interaction with the environment $(\mathrm{G} \times \mathrm{E})$ or both (Fig. 4).

What-won-where biplot for sheath blight. The what-won-where biplot demonstrated that only one megaenvironment existed in the

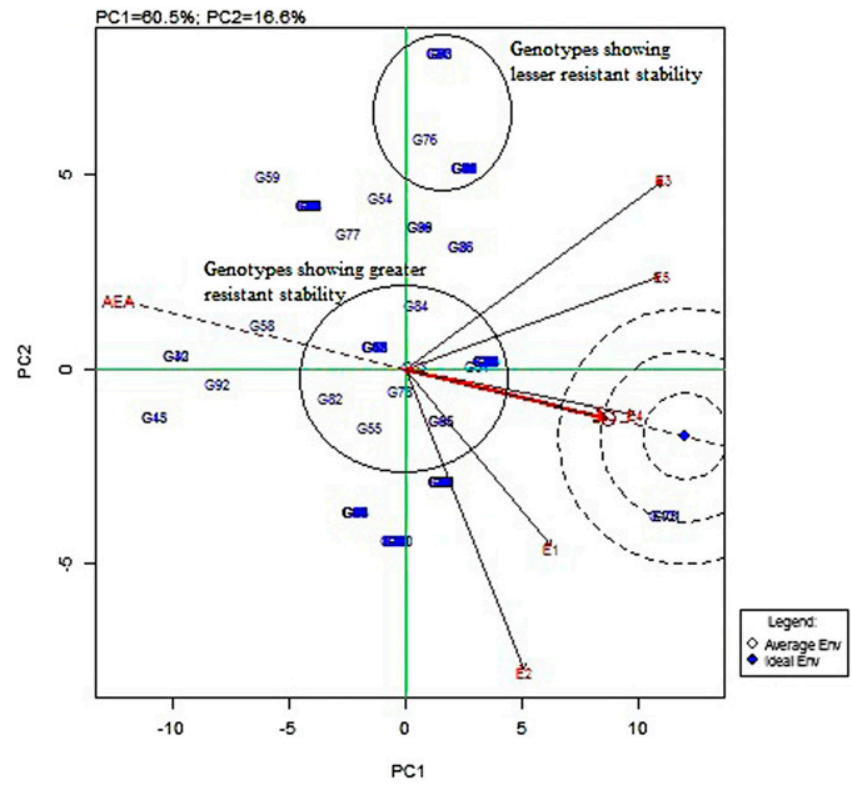

Fig. 4. Average environment coordination (AEC) view displaying the mean performance, ideal environment, and stability of the genotypes. E1, Burma, autumn 2015; E2, Burma, spring 2016; E3, Onverwagt Back, spring 2015; E4, Onverwagt Back, autumn 2015; E5, Onverwagt Back, spring 2016; G, genotype; PC, principal component. 
study (Fig. 5). The biplot indicated that all five test environments fall in one sector. Each megaenvironment sector showed different winning genotypes. The winner in this case was the genotypes that consistently showed disease susceptibility in all test environments. In this study, genotype G101 (Rustic) followed by G75 (GR1568-319-1-1-2-1) were identified as the winners within that megaenvironment displayed on the right side of the biplot. Likewise, opposite to this megaenvironment factor, genotypes G45 (GR1631-35-16-12-1-1), G92 (G98-135), G58 (IR-94), G59 (G11-08), G32 (GR1440-52-23-4-1-1-1-1-2-1-2), and G12 (FG12-41) falling within that megaenvironment were observed as having stable resistance to sheath blight. Furthermore, the genotypes clustered toward the origin of the biplot (G13: FG12-56; G23: FG12-270; G40: GR1602-6-41-11-2-1; and G89: FG07-35 GRDB-12) have been referred to as consistent and stable resistant lines to sheath blight (Fig. 5).

\section{Discussion}

Sheath blight is one of the major diseases in rice, and it has caused considerable reductions in grain yield and quality (Dubey et al. 2014). A major breeding goal for many rice-cultivating countries is the development of high-yielding cultivars with resistance to sheath blight. The use of resistance is regarded as the environment friendly and economical way of managing the sheath blight disease (Liu et al. 2009). Extensive research has been carried out over the years to identify resistant sources in rice germplasm (Dubey et al. 2014; Jia et al. 2012; Silva et al. 2012). In spite of evaluating $>30,000$ rice germplasm accessions, no effective source of resistance has been identified (Mew et al. 2004). However, few researchers have demonstrated large variations in the level of resistance to sheath blight under field conditions. Prasad and Eizenga (2008) identified moderately resistant Oryza meridionalis, Oryza barthii, Oryza nivara, Oryza officinalis, and $O$. sativa from wild species of the genus Oryza through laboratory, greenhouse, and field experiments. Similarly, Rush et al. (2011) have identified 25 germplasms as resistant and moderately resistant to sheath blight using the modified recurrent selection and backcross breeding methods. Gaihre and Nose (2013) reported indica variety Tetep expressing partial resistance against sheath blight.

This investigation revealed similar findings as elaborated above with respect to the variation in performance of genotypes against sheath blight. Of 101 genotypes evaluated, 13 were identified as elite

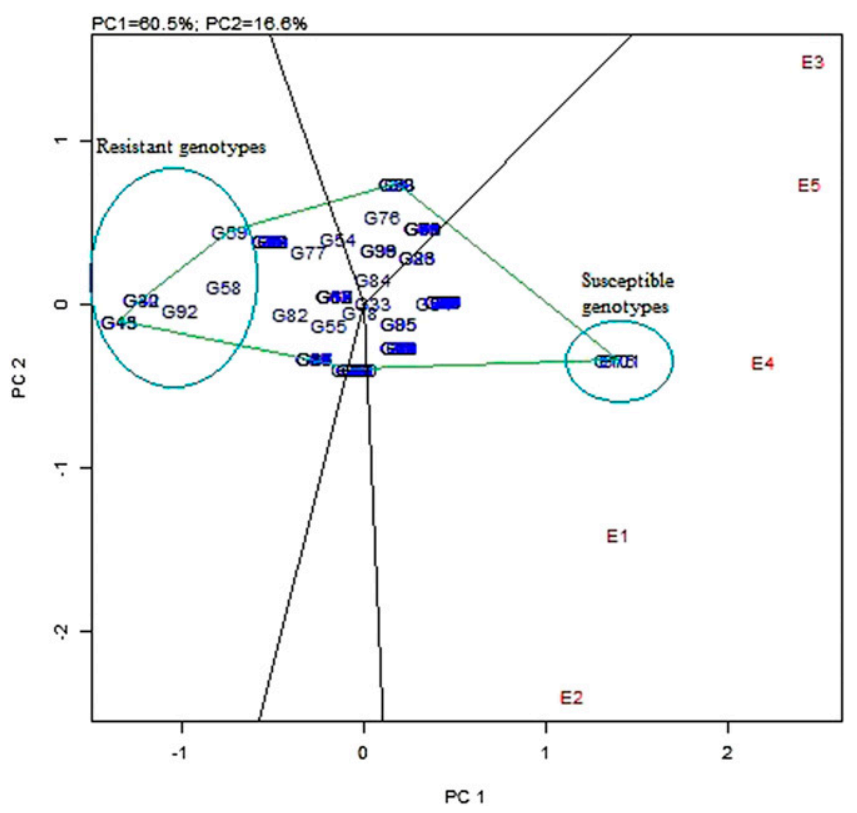

Fig. 5. The performance of genotypes in test environments in what-won-where view of genotype $\times$ environment biplot. E1, Burma, autumn 2015; E2, Burma, spring 2016; E3, Onverwagt Back, spring 2015; E4, Onverwagt Back, autumn 2015; E5, Onverwagt Back, spring 2016; G, genotype; PC, principal component. resistant sources against sheath blight. The genotypes (FG12-56 and GR1631-35-16-1-2-1-1) that showed immune response in one of the field experiments did not show the same level of immunity under artificial inoculated conditions. They showed resistant reactions against artificial inoculation of the pathogen, indicating the variations of screening under artificial and natural conditions. A similar finding was reported with the identification of two genotypes expressing immune reaction against sheath blight in rice (Persaud 2009).

The genotypes identified in this study with immune to resistant reaction, low AUDPC values, and slow apparent rate of disease development could be used as parents in breeding programs for development of resistant varieties against sheath blight disease. The inclusion of popular varieties in this study has identified cultivars G98-135, FG07-35, (GRDB-12) and BR-444 as resistant to sheath blight, and they could be further recommended to farmers for cultivation in disease-prone and endemic areas of Guyana.

The AMMI model first accounts for the main effects, and then, the PCA can be used to account for the interaction effects (Gauch 2006). The previous findings from various researchers have also confirmed that the AMMI analysis was useful in dissecting resistance levels of various genotypes (Mukherjee et al. 2013; Persaud and Saravanakumar 2018). In this study, the AMMI ANOVA of five environments showed that the $\mathrm{G} \times \mathrm{E}$ was almost as large as the genotype, thus indicating that the differences of the genotypes across the environment were sizeable. This further indicated that the resistance seemed to be influenced by the $\mathrm{G} \times \mathrm{E}$ factors. Cumulatively, PCA1 and PCA2 contributed to $68.50 \%$ of the total interaction. Thus, the interaction of the 101 genotypes across five test environments seemed to be best predicted by the first two principal components. Sufficient research reports have also stated that the genotype interactions were precisely predicted by two PCAs (Gauch and Zobel 1996; Mukherjee et al. 2013; Nayak et al. 2008; Yan et al. 2000).

The weather conditions were considered to be ideal for the occurrence of sheath blight during the test seasons of 2015 and 2016 at Onverwagt Back and Burma. The relative humidity, temperature, sunshine, and rainfall ranged from 85 to $98 \%$, from 21.8 to $31.2^{\circ} \mathrm{C}$, from 4.3 to $9.2 \mathrm{~h}$, and from 0.17 to $13.0 \mathrm{~mm}$, respectively. However, the field environments showed an opposite interaction pattern compared with artificially inoculated conditions at the greenhouse. This could be owing to the exposure of genotypes to the field conditions at the Onverwagt Back location and semicontrolled greenhouse conditions at Burma. Gauch (2013) stated that either environmental or ecological factors could cause the opposite interaction effects. This study has identified autumn season 2015 at Onverwagt Back as an ideal test environment for resistant screening. Genotype GR1568-31-9-1-1-2-1 and the check Rustic were identified as the susceptible entries in the megaenvironment. The similar finding was reported earlier from the use of the what-won-where biplot (Yan and Tinker 2006). The biplot showed that the majority of entries that clustered toward the origin have stable sheath blight-resistant status.

The genotypes identified with resistant reactions, relatively low AUDPC value, and decrease in the rate of disease development seemed to be promising resources for breeding sheath blight resistance. Nevertheless, it is important to state that the approach used in this research did not dissect the genes or mechanisms associated with sheath blight resistance. Therefore, additional research to identify the mechanisms at the molecular level would advance the development of molecular markers for screening resistant cultivars irrespective of environmental variations.

\section{Literature Cited}

Dubey, A. K., Pandian, R. T. P., Rajasekara, H., Kumari, M., and Singh, U. D 2014. Evaluation of rice genotypes for their reaction to sheath blight disease. Ann. Agri. Bio. Res. 19:737-740.

Gaihre, Y. R., and Nose, A. 2013. High yielding capabilities and genetic variation in crossing of sheath blight disease resistant rice line. Field Crops Res. 149: 133-140.

Gauch, H. G. 2006. Winning the accuracy game. Am. Sci. 94:133-141.

Gauch, H. G. 2007. Page 14853 in: MATMODEL (Version 3.0): Open Source Software for AMMI and Related Analyses. Crop and Soil Sciences. Cornell University, Ithaca, NY. 
Gauch, H. G. 2013. Review and interpretation: A simple protocol for AMMI analysis of yield trials. Crop Sci. 53:1860-1869.

Gauch, H. G., and Zobel, R. W. 1996. AMMI analysis of yield trials. Page 85-122 in: Genotype by Environment Interaction. M. S. Kang and H. G. Gauch, eds. CRC Press, Boca Raton, FL.

IRRI. 1988. Standard Evaluation System (SES) for Rice. IRRI, Manila, Philippines.

IRRI. 2014. PBTools Version 1.4. Biometrics and Breeding Informatics, PBGB Division, International Rice Research Institute, Los Baños, Laguna, Philippines.

Jia, L., Yan, W., Zhu, C., Agrama, H. A., Jackson, A., Yeater, K., Li, X., Huang, B., Hu, B., McClung, A., and Wu, D. 2012. Allelic analysis of sheath blight resistance with association mapping in rice. PLoS One 7:e32703.

Kazempour, M. N. 2004. Biological control of Rhizoctonia solani, the causal agent of sheath blight by antagonistics bacteria in green house and field condition. Plant Pathol. J. 3:88-96.

Liu, G., Jia, Y., Correa-Victoria, F. J., Prado, G. A., Yeater, K. M., McClung, A., and Correll, J. C. 2009. Mapping quantitative trait loci responsible for resistance to sheath blight in rice. Phytopathology 99:1078-1084.

Liu, G., Jia, Y., McClung, A., Oard, J. H., Lee, F. N., and Correll, J. C. 2013. Confirming QTLs and finding additional loci responsible for resistance to rice sheath blight disease. Plant Dis. 97:113-117.

Mew, T. W., Leung, H., Savary, S., Vera Cruz, C. M., and Leach, J. E. 2004. Looking ahead in rice disease research and management. Crit. Rev. Plant Sci. 23:103-127.

Miyake, I. 1910. Studies uber die pilze der reispflanzen in Japan. J. Coll. Agric. Imp. Univ. Tokyo 2:237-276.

Mukherjee, A. K., Mohapatra, N. K., Bose, L. K., Jambhulkar, N. N., and Nayak, P. 2013. Additive main effects and multiplicative interaction (AMMI) analysis of $\mathrm{G} \times \mathrm{E}$ interactions in rice-blast pathosystem to identify stable resistant genotypes. Afr. J. Agric. Res. 8:5492-5507.

Nayak, D., Bose, L. K., Singh, S., and Nayak, P. 2008. Additive main effects and multiplicative interaction analysis of host-pathogen relationship in rice bacterial-blight pathosystem. Plant Pathol. J. 24:337-351.

Ou, S. H. 1973. Page 76 in: A Handbook of Rice Diseases in the Tropics. IRRI, Los Banos, Laguna, Philippines.

Persaud, R. 2009. Studies on plant resistance against sheath blight of rice caused by Rhizoctonia solani Kühn. Master's thesis. The Indira Ghandhi Agricultural University, Raipur, India.

Persaud, R., Khan, A., Isaac, W., Ganpat, W., and Saravanakumar, D. 2019. Plant extracts, bioagents and new generation fungicides in the control of rice sheath blight in Guyana. Crop Prot. 119:30-37.
Persaud, R., and Saravanakumar, D. 2018. Screening for blast resistance in rice using AMMI models to understand $\mathrm{G} \times$ E interaction in Guyana. Phytoparasitica 46:551-568.

Pinson, S. R. M., Capdevielle, F. M., and Oard, J. H. 2005. Confirming QTLs and finding additional loci conditioning sheath blight resistance in rice using recombinant inbred lines. Crop Sci. 45:503-510.

Prasad, B., and Eizenga, G. C. 2008. Rice sheath blight disease resistance identified in Oryza spp. accessions. Plant Dis. 92:1503-1509.

Prescott, J. M., Burnett, P. A., Saari, E. E., Ransom, J., Bowman, J., Milliano, W. Singh, R. P., and Bekele, G. 1986. Wheat Diseases and Pests, a Guide for Field Identification. CIMMYT, Lisboa 27, Apdo, Mexico D.F., Mexico.

Rodrigues, P. C., Malosetti, M., Gauch, H. G., and Van Eeuwijk, F. A. 2014. A weighted AMMI algorithm to study genotype-by-environment interaction and QTL-by-environment interaction. Crop Sci. 54:1555-1570.

Rush, M. C., Groth, D. E., and Sha, X. 2011. Registration of 25 sheath blight diseaseresistant germplasm lines of rice with good agronomic traits. J. Plant Regist. 5:400-402.

Silva, J., Scheffler, B., Sanabria, Y., De Guzman, C., Galam, D., Farmer, A. Woodward, J., May, G., and Oard, J. 2012. Identification of candidate genes in rice for resistance to sheath blight disease by whole genome sequencing. Theor. Appl. Genet. 124:63-74.

Srinivasachary, S., Willocquet, L., and Savary, S. 2011. Resistance to rice sheath blight (Rhizoctonia solani Kühn) [(teleomorph: Thanatephorus cucumeris (A. B. Frank) Donk.] disease: Current status and perspectives. Euphytica 178:1-22.

Tang, Q., Peng, S., Buresh, R. J., Zou, Y., Castilla, N. P., Mew, T. W., and Zhong, X. 2007. Rice varietal difference in sheath blight development and its association with yield loss at different levels of $\mathrm{N}$ fertilization. Field Crops Res. 102:219-227.

Van Der Plank, J. E. 1963. Page 339 in: Plant Diseases: Epidemics and Control. Academic Press, New York, NY.

Willocquet, L., Fernandez, L., and Savary, S. 2000. Effect of various crop establishment methods practised by Asian farmers on epidemics of rice sheath blight caused by Rhizoctonia solani. Plant Pathol. 49:346-354

Willocquet, L., Lore, J. S., Srinivasachary, S., and Savary, S. 2011. Quantification of the components of resistance to rice sheath blight using a detached tiller test under controlled conditions. Plant Dis. 95:1507-1515.

Yadav, S., Anuradha, G., Kumar, R. R., Vemireddy, L. R., Sudhakar, R., Donempudi, K., Venkata, D., Jabeen, F., Narasimhan, Y. K., Marathi, B., and Siddiq, E. A. 2015. Identification of QTLs and possible candidate genes conferring sheath blight resistance in rice (Oryza sativa L.). Springerplus 4:175.

Yan, W., Hunt, L. A., Sheng, Q., and Szlavnics, Z. 2000. Cultivar evaluation and mega environment investigation base on GGE biplot. Crop Sci. 40:597-605.

Yan, W., and Tinker, N. A. 2006. Biplot analysis of multi-environment trial data: Principles and applications. Can. J. Plant Sci. 86:623-645. 